\title{
Effect of orally administered aqueous extracts of selected Jordanian plants and paracetamol on routine clinical chemistry tests in human volunteers
}

\author{
Nessrin G. Alabdallat \\ Department of Medical Laboratory Sciences, Collage of Applied Medical Sciences, Majmaah University, AL-Majmaah 11952, Saudi
} Arabia

\section{Article Info}

\section{Article history}

Received 14 October 2021

Revised 4 December 2021

Accepted 6 December 2021

Published Online 30 December 2021

Keywords
Oral administration
Aqueous extracts
Chemistry tests
Z. officinale
R. officinalis
V. triphylla
S. triloba
O. syriacum

\begin{abstract}
Medicinal herbs are commonly used by people in Jordan. In the current study, we attempt to see whether the oral administration of aqueous extracts and paracetamol on human volunteers for 5 days affect the results of clinical chemistry tests of serum. A total of 54 healthy volunteers were divided into six groups of nine, with the first five groups drinking 200-250 ml of aqueous extract from selected medicinal plants for five days and the sixth group taking two $500 \mathrm{mg}$ paracetamol tablets for five days. Blood samples were obtained before to set as the control group without any treatment and one hour after the first dose of administration in day 1 , as well as one day after the fifth dose in day 5 . The serum was subjected to 13 conventional clinical chemistry assays. Oral administration of aqueous extracts of R. officinalis, V.triphylla, Z.officinale, S.triloba and O.syriacum for 5 days cause a significant increase or decrease of some clinical chemistry tests (BUN, CREA and LDH; clinical parameters were decreased) compared to 0 time of administration. The potential risks of $O$. syriacum, increased ALP, S. triloba increased K and V. triphylla increased uric acid. Although, some clinical chemical tests were affected by these aqueous extracts, but these effects did not exceed the known normal ranges of these parameters, therefore it is concluded that the oral administration of aqueous extracts of tested herbs could significantly alter some laboratory results without exceed the normal range of results.
\end{abstract}

\section{Introduction}

Medicinal herbs play an important role in folk medicine in Jordan (Abdelhalim et al., 2017; Issa and Basheti, 2016; Issa and Basheti, 2017; Abu-Irmaileh and Afifi, 2003).

Rosmarinus. officinalis L. (Lamiaceae), the Arabic name is Ikleel alJabaland, English name is rosemary; it has been widely used in cooking to change and improve flavors, it is used to prevent and cure colds, rheumatism, pain of muscles and joints in folk medicine. rosmary extracts have a variety of pharmacological activities, such as antiinflammatory, antimicrobial, antioxidant, antidiabetic and antitumor activities (Faixová and Faix, 2008; Andrade et al., 2018; Rocha et al., 2015; Eilyad et al., 2012).

Zingiber officinale Roscoe belongs to the family of Zingiberaceae, ginger is the common name for Zingiber officinale Roscoe. Ginger extract has been examined for its pharmacological and biological effects, such as antioxidant, antiinflammatory, antimicrobial, antiobesity, antidiabetic, antinausea and antiemetic, cardiovascular protection, neuroprotection and antiallergen (Sharifi-Rad et al., 2017; Mao et al., 2019).

Corresponding author: Nessrin G. Alabdallat

Associate Professor in Haematology, Department of Medical Laboratory Sciences, Collage of Applied Medical Sciences, Majmaah University, AL-Majmaah 11952, Saudi Arabia

E-mail: n.alabdallat@mu.edu.sa

Tel.: +966-164042869

Copyright (C) 2021 Ukaaz Publications. All rights reserved.

Email: ukaaz@yahoo.com; Website: www.ukaazpublications.com
Salvia triloba, L., belongs to the Lamiaceae family, commonly referred to as Greek sage, the Arabic name is Meramiyyh is a native plant of the Mediterranean, which has been used in traditional medicine to treat gastric disorders, bloating, infections of the mouth, gums, and teeth, stomach discomfort, headaches, common cold, cough, and influenza (Abu-Irmaileh and Afifi, 2003; Abu-Rmailah and Afifi, 2000; Hala, 2006). S. triloba extracts have been shown to possess antioxidant, antiinflammatory, anticancer and antimicrobial activities (Kamatou et al., 2010; Kamatou et al., 2008; Kamatou et al., 2007; Kamatou et al., 2005; Hala, 2006).

Origanum syriacum L. (Lamiaceae), is often known as white oregano and/or Syrian oregano, and its Arabic name is za' atar (Zein et al., 2011). Previous studies have reported its antioxidant, antiinflammatory and anticholinesterase activities (Loizzo et al., 2009).

Verbena triphylla, L'Her, belongs to the Lamiaceae family, English name is lemon verbena, the arabic name is melissa. It is commonly used to treat abdominal pain, gynecological disorders, arthritis (AbuIrmaileh and Afifi, 2003; Abu-Rmailah and Afifi, 2000).

Paracetamol is a non-prescription analgesic and antipyretic medication that is available in mono- and multi-component formulations around the world.

The purpose of this study is to examine if oral administration of aqueous extracts of Z.officinale (rhizomes), R. officinalis (leaves), V. triphylla (leaves), S.trialob (leaves), O.syriacum (leaves) on human volunteers for 5 days affect the results of clinical chemistry tests of serum against the well-known drug paracetamol. 


\section{Materials and Methods}

\subsection{Plant material}

The selected plants Ginger (rhizomes), Rosemary (leaves), Melissa (leaves), Meramiyyh (leaves), Za' atar (leaves) were obtained at Madaba, Jordan's local herbal stores.

\section{i. Preparation of aqueous extracts}

$250 \mathrm{~g}$ of Ginger, Rosemary, Melissa, Meramiyyh and Za' atar were boiling at $100^{\circ} \mathrm{C}$ for $10-15 \mathrm{~min}$ and then soak for $4-5 \mathrm{~h}$ at $25^{\circ} \mathrm{C}$. The soaking or aqueous extract was then put into clean bottles (each one contains $1.250 \mathrm{l}$ ).

\section{ii. Samples of blood}

Table 1 shows the demographic characteristics of 54 healthy volunteers who were divided into six groups of nine. For five days, five groups drank $200-250 \mathrm{ml}$ of aqueous extracts of Ginger, Rosemary, Melissa, Meramiyyh, and Za'atar daily, while group six was given two $500 \mathrm{mg}$ paracetamol pills. In gell tubes, three (03) blood samples were taken from each healthy volunteer (before consuming aqueous extract ( 0 time), after $1 \mathrm{~h}$ of the first dose (drinking aqueous extract) on day 1 , and the next day following the last dose of day 5, day 6). To separate and collect serum, gell tubes were centrifuged for $10 \mathrm{~min}$ at $3000 \mathrm{xg}$ at $25^{\circ} \mathrm{C}$. The supernatant was collected after $2 \mathrm{ml}$ of distilled water was introduced to the cells under the gell in tubes, and the tubes were centrifuged for 5 $\mathrm{min}$ at $3000 \mathrm{xg}$ (hemolysate). Until analysis, all samples were maintained frozen at $-20^{\circ} \mathrm{C}$.

Table 1: Demographic data of participant

\begin{tabular}{|l|c|c|}
\hline Group & Age (Mean \pm S.D.) & Female/Male \\
\hline Origanum syriacum & $35.8 \pm 14.7$ & $4 / 5$ \\
Salvia triloba & $42.8 \pm 14.6$ & $6 / 3$ \\
Verbena triphylla & $34 \pm 18.6$ & $4 / 5$ \\
Zingiber officinale & $41.8 \pm 7.6$ & $7 / 2$ \\
Paracetamol & $30.6 \pm 9.8$ & $3 / 6$ \\
Rosmarinus officinalis & $35.4 \pm 13.5$ & $4 / 5$ \\
\hline
\end{tabular}

iii. Measurement of clinical chemistry parameters

The kits for measuring clinical chemistry parameters were purchased commercially from Roche, and the parameters were measured using a Hitachi 902 analyzer. Table 2 shown theclinical chemistry parameters measured.

Table 2: Clinical chemistry parameters measured

\begin{tabular}{|l|l|}
\hline Serum total protein (TP) & Serum albumin (ALB) \\
Serum lactate dehydrogenase (LDH) & Serum aspartate aminotransferase (AST) \\
Serum alanine aminotransferase (ALT) & Serum alkaline phosphatase (ALP) \\
Serum urea nitrogen (BUN) & Serum creatinine (CREA) \\
Serum uric acid (UA) & Serum sodium (NA) \\
Serum potassium (K) & Serum creatinine phosphokinase (CPK) \\
Serum amylase (Amyl) & - \\
\hline
\end{tabular}

\section{iv. Normal range (Reference value) for serum chemistries}

$\mathrm{K}$ ref value $=3.7-5.2 \mathrm{mmol} / \mathrm{l}, \mathrm{Na}$ ref value $=135-145 \mathrm{mmol} / \mathrm{l}$, BUN ref value $=6-20 \mathrm{mg} / \mathrm{dl}$ ), CREA ref value $=0.6-1.3 \mathrm{mg} / \mathrm{dl}$, UA ref value $=3.5-7.2 \mathrm{mg} / \mathrm{dl}, \mathrm{ALB}$ ref value $=34-54 \mathrm{~g} / \mathrm{l}, \mathrm{TP}$ ref value $=60$ $859 / 1$, ALP ref value $=55-142 \mathrm{U} / 1$, AST ref value $=8-40 \mathrm{U} / 1$, ALT ref value $=7-55 \mathrm{U} / \mathrm{l}, \mathrm{CPK}$ ref value $=38-176 \mathrm{U} / \mathrm{l}, \mathrm{LDH}$ ref value $=$ 200-450 U/l), AMY ref value $=40-140 \mathrm{U} / 1$.

\section{v. Statistical Analysis}

All data are reported as the mean \pm S.D. Statistical analysis was performed using SPSS statistics 17 . The results were compared by paired t-test. The results with a valueof $p<0.05$ were considered significant.

\section{Results}

Tables 3-5 show the effects of studied plants on serum clinical chemistry parameters. At the sixth day of administration (i.e., one day following the last dose of day five) $S$. triloba caused a significant increase in serum potassium and uric acid and a significant decreasein serum BUN and lactate (LDH) dehydrogenase. Z. officinale caused a significant decrease in serum potassium and BUN and a significant increase in serum creatinine phosphokinase (CPK). O. syriacum caused a significant decrease in serum BUN and lactate dehydrogenase (LDH) and a significant increase in serum alkaline phosphatase. V. triphylla caused a significant decrease in serum BUN and creatinine and significant increase in serum uric acid. paracetamol caused a significant increase in serum potassium and albumin and a significant decreased in serum creatinine, uric acid and creatinine phosphokinase (CPK). R. officinalis had no significant effect on the levels of tested biochemical parameters. However, the effects of tested plants on serum biochemical parameters were all within the known normal ranges of these parameters. However, serum Na, AST and ALT were not affected by any of tested plants. 
Table 3: The following parameters were affected by the given medicinal plants. Each value represents the mean value \pm SD, $(\mathrm{n}=8-10) *{ }^{*} p<0.05$, compared to 0 time administration

\begin{tabular}{|l|c|c|c|c|c|c|c|c|c|}
\hline & \multicolumn{3}{|c}{ K } & \multicolumn{3}{c|}{ BUN } & \multicolumn{3}{c|}{ CREA } \\
\cline { 2 - 10 } & 0 time & $\mathbf{1 ~ h}$ & Day $\mathbf{6}$ & $\mathbf{0 ~ t i m e}$ & $\mathbf{1 ~ h}$ & Day $\mathbf{6}$ & $\mathbf{0 ~ t i m e}$ & $\mathbf{1 ~ h}$ & Day $\mathbf{6}$ \\
\hline Origanum syriacum & $4.2 \pm 0.43$ & $4.4 \pm 0.27$ & $4.4 \pm 0.25$ & $15.4 \pm 3.8$ & $14.3 \pm 3.8^{*}$ & $11.2 \pm 2.1^{*}$ & $0.78 \pm 0.18$ & $0.73 \pm 0.17$ & $0.73 \pm 0.0 .14$ \\
Salvia triloba & $4.0 \pm 0.47$ & $4.0 \pm 0.39$ & $4.3 \pm 0.3^{*}$ & $14.7 \pm 4.7$ & $14.1 \pm 4.7^{*}$ & $11.6 \pm 3.7^{*}$ & $0.71 \pm 0.20$ & $0.70 \pm 0.19$ & $0.69 \pm 0.19$ \\
Verbena triphylla & $4.38 \pm 0.40$ & $4.4 \pm 0.21$ & $4.34 \pm 0.38$ & $13.5 \pm 3.5$ & $13.0 \pm 2.8$ & $9.7 \pm 2.0^{*}$ & $0.74 \pm 0.13$ & $0.72 \pm 0.13$ & $0.65 \pm 0.16^{*}$ \\
Zingiber officinale & $4.3 \pm 0.47$ & $4.3 \pm 0.53$ & $4.0 \pm 0.26^{*}$ & $17.9 \pm 4.5$ & $16.6 \pm 4.5^{*}$ & $13.5 \pm 3.6^{*}$ & $0.67 \pm 0.14$ & $0.67 \pm 0.13$ & $0.62 \pm 0.12$ \\
Rosmarinus officinalis & $4.4 \pm 0.39$ & $4.6 \pm 0.35$ & $4.4 \pm 0.29$ & $12.6 \pm 2.2$ & $12.6 \pm 1.5$ & $10.2 \pm 1.9$ & $0.78 \pm 0.20$ & $0.78 \pm 0.21$ & $0.76 \pm 0.26$ \\
Paracetamol & $4.33 \pm 0.42$ & $4.49 \pm 0.54$ & $4.72 \pm 0.30^{*}$ & $12.6 \pm 3.4$ & $12.8 \pm 3.6$ & $15.0 \pm 5.1$ & $0.86 \pm 0.16$ & $0.94 \pm 0.20$ & $0.82 \pm 0.18^{*}$ \\
\hline
\end{tabular}

Table 4: The following parameters were affected by the given medicinal plants. Each value represents the mean value \pm SD, $(\mathrm{n}=8-10), * p<0.05$, compared to 0 time administration

\begin{tabular}{|l|r|r|r|r|r|r|r|r|c|c|}
\hline & \multicolumn{3}{|c|}{ U.A. } & \multicolumn{3}{c|}{ ALP } & \multicolumn{3}{c|}{ CPK } \\
\cline { 2 - 10 } & $\mathbf{0 ~ t i m e}$ & $\mathbf{1 ~ h}$ & Day 6 & 0 time & $\mathbf{1 ~ h}$ & Day 6 & 0 time & $\mathbf{1 ~ h}$ & Day 6 \\
\hline Origanum syriacum & $5.0 \pm 1.1$ & $5.0 \pm 1.0$ & $5.0 \pm 1.0$ & $67.6 \pm 24.0$ & $65.9 \pm 21.2$ & $70.6 \pm 23.2^{*}$ & $100.7 \pm 31.2$ & $106.8 \pm 34.8$ & $121.7 \pm 57.2$ \\
Salvia triloba & $3.95 \pm 1.7$ & $3.90 \pm 1.7$ & $4.27 \pm 1.8^{*}$ & $98.5 \pm 64.8$ & $97.2 \pm 64.8$ & $96.1 \pm 61.0$ & $100.0 \pm 58.4$ & $102.9 \pm 59.0$ & $118.7 \pm 81.0$ \\
Verbena triphylla & $4.92 \pm 1.0$ & $5.0 \pm 1.0^{*}$ & $5.4 \pm 1.3^{*}$ & $112.9 \pm 71.5$ & $110.3 \pm 67.2$ & $112.0 \pm 78.3$ & $90.5 \pm 65.7$ & $93.0 \pm 64.4$ & $80.5 \pm 35.8$ \\
Zingiber officinale & $4.6 \pm 1.1$ & $4.7 \pm 1.1$ & $4.6 \pm 0.84$ & $76.1 \pm 22.8$ & $75.8 \pm 23.0$ & $77.9 \pm 22.8$ & $63.1 \pm 23.9$ & $67.6 \pm 22.6^{*}$ & $82.7 \pm 32.5^{*}$ \\
Rosmarinus officinalis & $5.4 \pm 1.8$ & $5.4 \pm 1.7$ & $5.6 \pm 1.8$ & $130.2 \pm 86.9$ & $126.8 \pm 84.0$ & $126.3 \pm 82.8$ & $124.0 \pm 71.8$ & $121.1 \pm 64.8$ & $121.0 \pm 50.0$ \\
Paracetamol & $6.3 \pm 2.2$ & $6.4 \pm 2.0$ & $5.9 \pm 2.3^{*}$ & $102.1 \pm 30.6$ & $103.8 \pm 32.5$ & $98.4 \pm 32.4$ & $194.6 \pm 266.8$ & $179.2 \pm 231.5$ & $100.9 \pm 73.7 *$ \\
\hline
\end{tabular}

Table 5: The following parameters were affected by the given medicinal plants. Each value represents the mean value \pm SD, $(\mathrm{n}=8-10), * p<0.05$, compared to 0 time administration

\begin{tabular}{|c|c|c|c|c|c|c|c|c|c|c|c|c|}
\hline & \multicolumn{3}{|c|}{ LDH } & \multicolumn{3}{|c|}{ ALB } & \multicolumn{3}{|c|}{ TP } & \multicolumn{3}{|c|}{ AMYL } \\
\hline & 0 time & $1 \mathrm{~h}$ & Day 6 & 0 time & $1 \mathrm{~h}$ & Day 6 & 0 time & $1 \mathrm{~h}$ & Day 6 & 0 time & $1 \mathrm{~h}$ & Day 6 \\
\hline $\begin{array}{l}\text { Origanum } \\
\text { syriacum }\end{array}$ & $350.5 \pm 54.5$ & $350.2 \pm 66.5$ & $322.5 \pm 39.9^{*}$ & $46.6 \pm 3.8$ & $45.9 \pm 3.9$ & $47.7 \pm 4.0$ & $77.3 \pm 6.1$ & $75.8 \pm 5.4$ & $80.2 \pm 6.4$ & $58.1 \pm 12.8$ & $55.9 \pm 13.4$ & $63.1 \pm 16.0$ \\
\hline Salvia triloba & $355.2 \pm 38.5$ & $346.1 \pm 37.4$ & $318.3 \pm 40.5^{*}$ & $47.0 \pm 3.5$ & $46.6 \pm 3.0$ & $46.2 \pm 3.6$ & $80.0 \pm 4.6$ & $79.3 \pm 4.7$ & $79.8 \pm 3.0$ & $67.4 \pm 20.2$ & $65.3 \pm 16.3$ & $66.8 \pm 19.3$ \\
\hline $\begin{array}{l}\text { Verbena } \\
\text { triphylla }\end{array}$ & $307.3 \pm 48.0$ & $317 \pm 48.2$ & $304.4 \pm 39.7$ & $45.2 \pm 2.2$ & $44.6 \pm 2.5$ & $46.6 \pm 3.8$ & $77.6 \pm 3.9$ & $76.1 \pm 2.1$ & $79.7 \pm 4.4$ & $46.8 \pm 15.2$ & $45.9 \pm 14.7$ & $43.3 \pm 16.6$ \\
\hline $\begin{array}{l}\text { Zingiber } \\
\text { officinale }\end{array}$ & $375.0 \pm 48.7$ & $371.9 \pm 42.6$ & $370.5 \pm 37.4$ & $44.8 \pm 2.8$ & $45.4 \pm 2.2$ & $44.5 \pm 2.3$ & $77.7 \pm 4.9$ & $78.1 \pm 3.6$ & $77.9 \pm 4.9$ & $57.3 \pm 14.3$ & $55.7 \pm 13.7$ & $55.8 \pm 15.8$ \\
\hline $\begin{array}{l}\text { Rosmarinus } \\
\text { officinalis }\end{array}$ & $403.5 \pm 105.9$ & $374.6 \pm 79.7$ & $358.9 \pm 66.9$ & $47.2 \pm 4.6$ & $45.3 \pm 3.5$ & $46.6 \pm 3.4$ & $79.4 \pm 6.7$ & $77.4 \pm 4.8$ & $81.5 \pm 5.5$ & $51.2 \pm 16.3$ & $49.3 \pm 14.1$ & $50.2 \pm 15.0$ \\
\hline Paracetamol & $388.0 \pm 48.7$ & $381 \pm 46.3$ & $367.6 \pm 43.5$ & $46.3 \pm 4.0$ & $46.2 \pm 1.6$ & $49.3 \pm 3.4$ & $81.6 \pm 5.4$ & $81.6 \pm 3.1$ & $82.6 \pm 3.2$ & $52.8 \pm 9.7$ & $54.2 \pm 10.7$ & $56.5 \pm 8.9$ \\
\hline
\end{tabular}

Table 6: The following parameters were not affected by the given medicinal plants. Each value represents the mean value \pm $\mathrm{SD},(\mathrm{n}=8-10)$.

\begin{tabular}{|c|c|c|c|c|c|c|c|c|c|}
\hline & \multicolumn{3}{|c|}{ AST } & \multicolumn{3}{|c|}{ ALT } & \multicolumn{3}{|c|}{$\mathrm{Na}$} \\
\hline & 0 time & $1 \mathrm{~h}$ & Day 6 & 0 time & $1 \mathrm{~h}$ & Day 6 & 0 time & $1 \mathrm{~h}$ & Day 6 \\
\hline Origanum syriacum & $21.6 \pm 11.2$ & $22.4 \pm 10.9$ & $21.2 \pm 6.3$ & $21.5 \pm 16.4$ & $21.9 \pm 16.1$ & $20.6 \pm 12.3$ & $145.1 \pm 1.4$ & $144.3 \pm 1.6$ & $146.0 \pm 2.0$ \\
\hline Salvia triloba & $23.0 \pm 6.0$ & $22.7 \pm 7.4$ & $22.3 \pm 8.0$ & $26.2 \pm 16.3$ & $26.2 \pm 17.5$ & $26.2 \pm 18.3$ & $144.6 \pm 1.6$ & $145.6 \pm 1.0$ & $145.6 \pm 3$ \\
\hline Verbena triphylla & $15.8 \pm 5.7$ & $16.2 \pm 5.0$ & $16.4 \pm 5.4$ & $17.4 \pm 13.3$ & $17.5 \pm 14.1$ & $18.9 \pm 15.7$ & $146.0 \pm 2.2$ & 144. \pm 1.2 & $145.4 \pm 1.7$ \\
\hline Zingiber officinale & $22.8 \pm 19.0$ & $23.3 \pm 17.6$ & $19.5 \pm 6.7$ & $22.9 \pm 26.8$ & $23.5 \pm 26.6$ & $19.6 \pm 13.0$ & $144.9 \pm 1.9$ & $143.8 \pm 1.6$ & $145.5 \pm 1.3$ \\
\hline Rosmarinus officinalis & $25.5 \pm 6.7$ & $25.2 \pm 7.2$ & $24.0 \pm 5.7$ & $27.6 \pm 15.6$ & $26.7 \pm 14.1$ & $27.2 \pm 16.7$ & $148.1 \pm 2.3$ & $148.5 \pm 1.5$ & $147.9 \pm 4.8$ \\
\hline Paracetamol & $26.1 \pm 8.7$ & $25.9 \pm 7.6$ & $24.1 \pm 7.5$ & $38.9 \pm 28.3$ & $37.9 \pm 26.6$ & $36.3 \pm 23.8$ & $146.0 \pm 2.8$ & $144.5 \pm 2.1$ & $146.5 \pm 2.0$ \\
\hline
\end{tabular}




\section{Discussion}

Many studies reported that collective use of tea with related polyphenols and market-based drugs can ameliorate the treatment way for the disease specifically which are caused by the microorganisms and other toxicants (Sanlier et al., 2018). Study by Toda et al. (1989) reported the daily moderated consumption of tea can kill many microbes like Staphylococcus aureus, Vibrio parahemolyticus, Clostridium perfringens, Bacillus cereus, Pleisomonas shigelloides, as tea contains 30 to $4 \%$ of water extractable polyphenolic compound (Toda et al., 1989). Apart from that this herbal therapy is also found to be effective equally with the normal analgesic drugs (Chevallier, 2016; Zhu et al., 2008). The herbal therapy is useful for lowering the side effects of the commercially available medicines, and therefore, it can be used as potential treatment of the normal analgesic symptoms for which people used take commercial medicine without prescriptions. The four most abundantly found polyphenolic compounds; epigallocatechingallate (EGCG), epicatechingallate (ECG), epigallocatechin (EGC) and epicatechin (EC) are significantly recorded in tea especially green tea extract as reported in study of Diane et al. (2007). In other studies, herbal amalgam of commercial drug tamoxifen and epigallocatechingallate (EGCG) is used as the effective induced apoptotic agents in comparison to the separate one against cancer cells (Chisholm et al., 2004).

In the present study, although the results obtained show some significant increase in some clinical chemistry parameters and some even decreased as recorded in serum when the effect of tested plants were recorded, but these changes were minimal and did not exceed the known normal ranges for these parameters.

Therefore, it is important for future studies to test the effects of these herbal extracts on laboratory methods by direct addition of these extracts to test tubes along with the serum samples. The present study is involving a small number of participants for a short period. Thus, further studies may be needed to clarify the effects of long-term use of these herbs and the related mechanisms on laboratory testing on large sample size.

A small sample size may make it difficult to determine if a particular outcome is a true finding and it considered as one of the study limitations.

\section{Conclusion}

Since the present study was performed on healthy individuals, one could speculate that the altered laboratory test results by a given herb could be considered as a beneficial effect and/or a side/adverse effect. This phenomenon was obvious in the present study with some tests, showing a beneficial effect of reducing some blood parameters such as BUN and CREA.The effects of tested herbs on the following tests; increased UA, ALP, CPK, ALP, ALB, TP and AMYL and decreased LDH activity cannot be explained as neither positive or negative effects, but overall speaking they should be considered as confusing effects that could lead to confusion in patient's diagnosis and/or treatment.

From our study, it is speculated that herbal plants and their extract are equally beneficial as the commercial drugs but with least side effects.

\section{Ethics statement}

This study was carried out in compliance with the ethical principles outlined in the Helsinki Declaration of 1964. Prior to participating in the study, each individual subject gave their informed permission.

\section{Conflict of interest}

The author declares no conflicts of interest relevant to this article.

\section{Contributions of the authors}

NA designed the study and performed data collection, processing, and analysis.

\section{Acknowledgements}

The author is thankful to the Deanship of Scientific Research at Majmaah University for supporting this work under Project Number R-2021-327.

\section{References}

Abdelhalim, A.; Aburjai, T.; Hanrahan, J. and Halim, H. (2017). Medicinal plants used by traditional healers in Jordan, the Tafila region. Pharmacognosy Magazine, 13(49):1-10.

Abu-Irmaileh, B. E. and Afifi, F. U. (2003). Herbal medicine in Jordan with special emphasis on commonly used herbs. Journal of Ethnopharmacology, 89(2-3):283-289.

Abu-Rmailah, B. and Afifi, F. (2000). Treatment with medicinal plants in Jordan. Dirasat. Medical and Biological Sciences, 27:53-74.

Andrade, J. M.; Faustino, C.; Garcia, C.; Ladeiras, D.; Reis, C.P. and Rijo, P.(2018). Rosmarinus officinalis L.: An update review of its phytochemistry and biological activity. Future Sci. OA. Apr., 4(4):FSO283.

Chevallier, A. (2016). Encyclopedia of Herbal Medicine: 550 Herbs and Remedies for Common Ailments. Penguin.

Chisholm, K.; Bray, B. J. and Rosengren, R. J. (2004). Tamoxifen and epigallocatechingallate are synergistically cytotoxic to MDAMB-231 human breast cancer cells. Anticancer Drugs, 15(9):889897.

Diane, L. M. and Jeffrey, B. B (2007). Roles for epigallocatechingallate in cardiovascular disease and obesity: An introduction. Journal of the American College of Nutrition, 26(4):362S-365S.

Eilyad, I.;Parviz, K.;Mohammad, T. and Reza, F. (2012). Antimicrobial effects of rosemary (Rosmarinus officinalis L.) essential oils against Staphylococcus spp. African Journal of Microbiology Research, 6(23): 5039-5042.

Faixová, Z. and Faix, Š (2008). Biological effects of rosemary (Rosmarinus offficinalis L.) essential oil (A review). FOLIA VETERINARIA, 52(3-4):135-39.

Gali-muhtasib, H. (2006). Anticancer and medicinal properties of essential oil and extracts of East Mediterranean sage (Salvia triloba). Advances in Phytomedicine, 2:169-180

Issa, R. A. and Basheti, I.A. (2016). Herbal products use among Chronic patients and its impact on treatments safety and efficacy: A clinical survey in the Jordanian field. Trends in Medical Research, 12(1):3244.

Issa, R. A. and Basheti, I.A. (2017). Herbal medicine use by people in Jordan: Exploring believes and knowledge of herbalists and their customers. Journal of Biological Sciences, 17(8):400-409. 
Kamatou, G.P.P.; Van Vuuren, S.F.; Van Heerden, F.R.; Seaman, T. and Viljoen, A.M. (2007). Antibacterial and antimycobacterial activities of South African Salvia species and isolated compounds from $S$. chamelaeagnea. South African Journal of Botany, 73:552-557.

Kamatou, G.P.P.; Van Zyl, R.L.; Davids, H.; Van Heerden, F.R.; Lourens, A.C.U and Viljoen, A.M. (2008). Antimalarial and anticancer activities of selected South African Salvia species and isolated compounds from S. radula. South African Journal of Botany, 74:238-243.

Kamatou, G.P.P.; Viljoen, A.M.; Gono-Bwalya, A.B.; van Zyl, R.L.; van Vuuren, S.F.; Lourens, A.C.U.; Ba ${ }^{\circ}$ er, K.H.C.; Demirci, B.; Lindsey, K.L.; van Staden, J. and Steenkamp, P. (2005). The in vitro pharmacological activities and a chemical investigation of three South African Salvia species. Journal of Ethnopharmacology, 102:382-390.

Kamatou, G.P.P.; Viljoen, A.M. and Steenkamp, P. (2010). Antioxidant, antiinflammatory activities and HPLC analysis of South African Salvia species. Food Chemistry, 119:684-688.

Loizzo, M.R.;Menichini, F.; Conforti, F.; Tundis, R.;Bonesi, M. and Saab, A.M.(2009). Chemical analysis, antioxidant, antiinflammatory and anticholinesterase activities of Origanum ehrenbergii Boiss and Origanum syriacum L. essential oils. Food Chem., 117:174-180.

Mao, Q.; Xu, X. and Cao, S. (2019). Bioactive compounds and bioactivities of ginger (Zingiber officinale Roscoe). Foods Jun., 8(6):185.
Rocha, J.; Eduardo-Figueira, M.; Barateiro, A.; Fernandes, A.; Brites, D.; Bronze, R.; Duarte, C. M.; Serra, A. T.; Pinto, R.; Freitas, M.; Fernandes, E.; SilvaLima, B.;Mota-Filipe, H. and Sepodes, B. (2015). Antiinflammatory effect of rosmarinic acid and an extract of Rosmarinus officinalis in rat models of local and systemic inflammation. Basic and Clinical Pharmacology and Toxicology, 116:398-413.

Sanlier, N.; Gokcen, B. B. and Altuð, M. (2018). Tea consumption and disease correlations. Trends in Food Science and Technology, 78:95-106.

Sharifi-Rad, M.;Varoni, E.M. and Salehi, B.(2017). Plants of the genus zingiber as a source of bioactive phytochemicals: From Tradition to Pharmacy. Molecules, 22(12):2145.

Toda, M.; Okubo, S.; Hiyoshi, R. and Shimamura, T.(1989). Antibacterial and bactericidal activities of Japanese green tea. Jpn. J. Bacteriol, 44(4):669-672.

Zein, S.; Awada, S.; Rachidi, S.; Hajj, A.; Krivoruschko, E. and Kanaan, H. (2011). Chemical analysis of essential oil from Lebanese wild and cultivated Origanum syriacum L. (Lamiaceae) before and after flowering. J. Med. Plants Res., 5:379-387.

Zhu, X.; Proctor, M.; Bensoussan, A.; Wu, E. and Smith, C. A. (2008). Chinese herbal medicine for primary dysmenorrhoea. Cochrane Database of Systematic Reviews, 11(2):440-450. 